\title{
GIS based study on liquefaction-induced soil subsidence, a case from Urayasu area, Chiba, Japan
}

\author{
* Rama Mohan Pokhrel', Takashi Kiyota ${ }^{2}$ \\ ${ }^{1}$ Central Department of Geology, Tribhuvan University, Kirtipur, Kathmandu, Nepal \\ ${ }^{2}$ Institute of Industrial Science, University of Tokyo, Japan
}

\begin{abstract}
Urayasu City in Chiba prefecture, Japan, which is composed of young reclaimed land. Following the 2011 off the Pacific Coast of Tohoku Earthquake (M=9), severe liquefaction-induced ground subsidence was extensively observed in this young filled land. The major problems associated with liquefaction and ground subsidence like tilting of houses, buckling of roads and lifelines cut off were commonly observed. Therefore, a detailed study on possibility and amount of ground subsidence is essential to carry out in such area. In this paper, a variation of ground subsidence is studied after severe liquefaction takes place in an earthquake. Randomly distributed borehole locations were selected and calculated the liquefaction potential for each boreholes. Geostatistical method of interpolation a kriging method was applied to attain a spatial variation of liquefaction potential within the area by using selected borehole locations. The ground subsidence was estimated by using airborne LiDAR (Light Detection And Ranging) images before and after the earthquake which gives the spatial distribution of soil subsidence map. The liquefaction potential value was picked up from the liquefaction potential distribution map and the subsidence value of the corresponding points were picked up from the ground subsidence map. By comparing these two values the relationship between liquefaction potential and ground subsidence has been developed.
\end{abstract}

Keywords: Soil subsidence, liquefaction, land reclamation, Urayasu

Received: 19 December 2015

Revision accepted: 21 April 2016

\section{INTRODUCTON}

Soil liquefaction is one of the most serious geotechnical issue related to earthquakes that may induce severe ground subsidence, lateral spreading, tilt of super structures, and upliftment of light underground structures especially in a young alluvial deposit or reclaimed land. For example, Urayasu City in Chiba prefecture, Japan, which is geologically composed of newly reclaimed land (the reclamation in Urayasu city area was started in 1966 and completed in 1985), severely suffered from liquefaction at the time of 2011 off the Pacific Coast of Tohoku Earthquake ( $M=9.0)$. Not only Urayasu City, the liquefaction affects many cities of the north east coast of the Japan (Habib et al. 2012). Fig.1 shows a manhole uplifted at the time of liquefaction in Urayasu city. About 85 percent of the Urayasu city area was liquefied and was heavily damaged (Yasuda et al. 2012). In Urayasu, soil dredged from the bottom of the sea was filled up to the height of about sea level in the reclamation work and the filled surface was covered with hill sand transported by boat from the Boso Peninsula (Yasuda et al. 2012). Therefore the soil in the Urayasu reclaimed land area is high prone to liquefaction. In this paper, a detailed study is carried out and presented to evaluating the spatial distribution of liquefaction potential and soil subsidence in the area of Urayasu city. For the present study, 23 boreholes were selected (Urayasu city 2012) shown in Fig. 2, and calculated the liquefaction potential at borehole points with peak ground acceleration of 173 gal. A geostatistical method of interpolation in a Geographic Information System (GIS) is used to evaluate the spatial distribution of liquefaction potential in the area. This method gives the liquefaction potential value at each point. Similarly the soil subsidence map of this area is prepared by analyzing DSM data taken before earthquake on 2006 and after the earthquake 2011. By comparing point to point Pl value from Liquefaction potential distribution map and corresponding point to point subsidence value from soil subsidence distribution map, the relationship between liquefaction potential and ground subsidence is developed.

\section{METHODOLOGY}

\section{Liquefaction potential distribution map}

For the liquefaction potential zoning, the main step is collection of geotechnical data from boreholes and calculation of factor of safety against liquefaction for a given soil layer was evaluated by using the equation.

$$
F_{L}=\frac{R}{L}
$$

where $F_{L}<1$ indicates liquefaction, and $F_{L} \geq 1$ indicates non liquefaction. In this method, $\mathrm{R}$ is dynamic shear strength ratio and $\mathrm{L}$ is the seismic shear stress ratio at depth $\mathrm{z}$ that can be estimated simply by;

$$
L=\frac{\sigma_{0}}{\sigma_{0}^{\prime}} \frac{\alpha_{\max }}{g} r_{d}
$$

where $\alpha$ max is the maximum acceleration at the ground surface (in gals), $\mathrm{g}$ is the acceleration due to gravity (=980 gals), $\sigma_{0}$ is the total overburden pressure, $\sigma_{0}$ ' is effective stress and $r_{d}$ is the reduction factor of dynamic shear stress accounting for the deformation of the ground and is expressed as, 


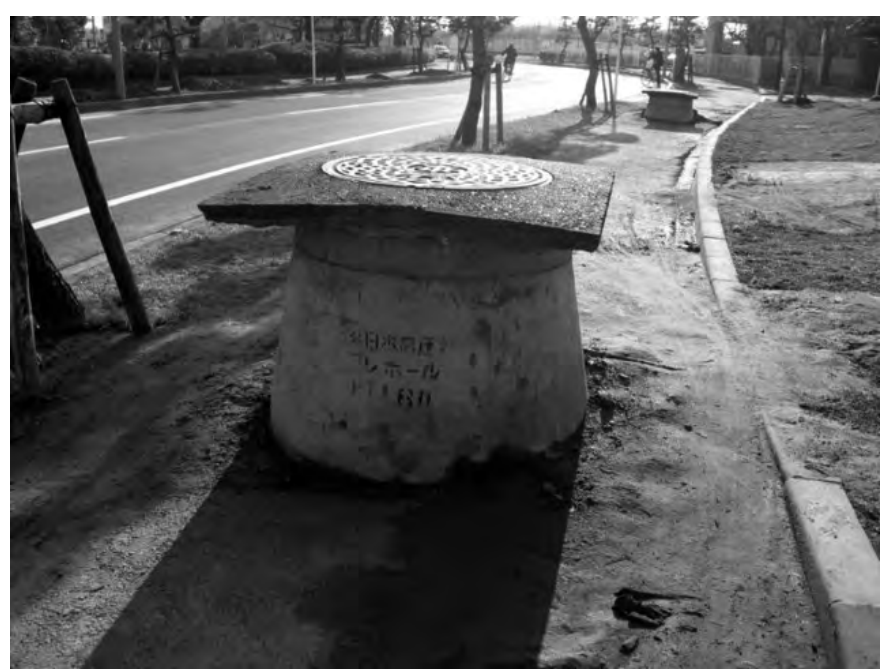

Fig. 1: Manhole uplifted during earthquake March 2011 in Urayasu area.

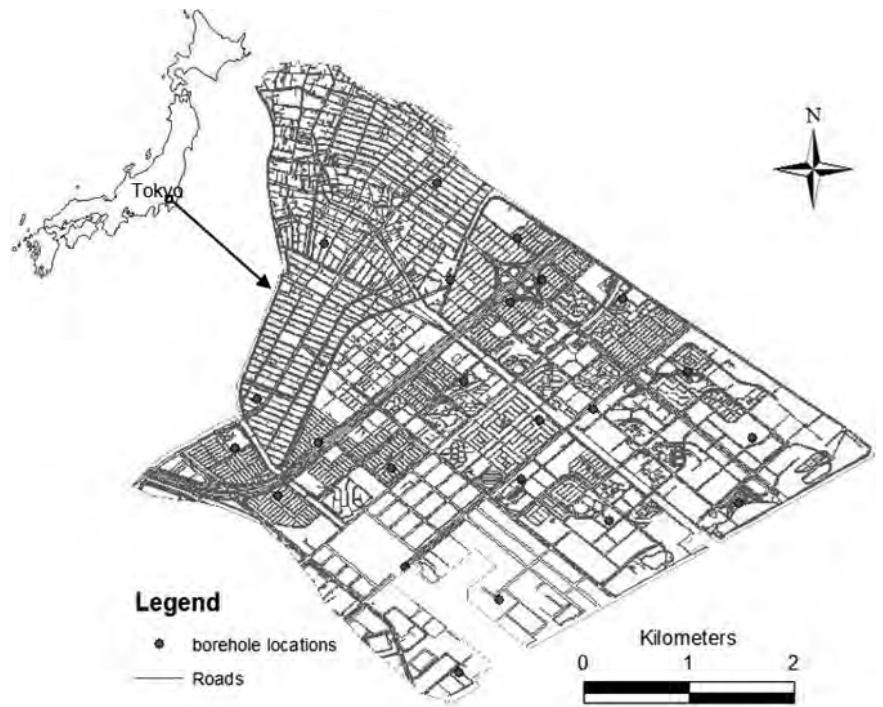

Fig. 2: Location of study area with borehole points.

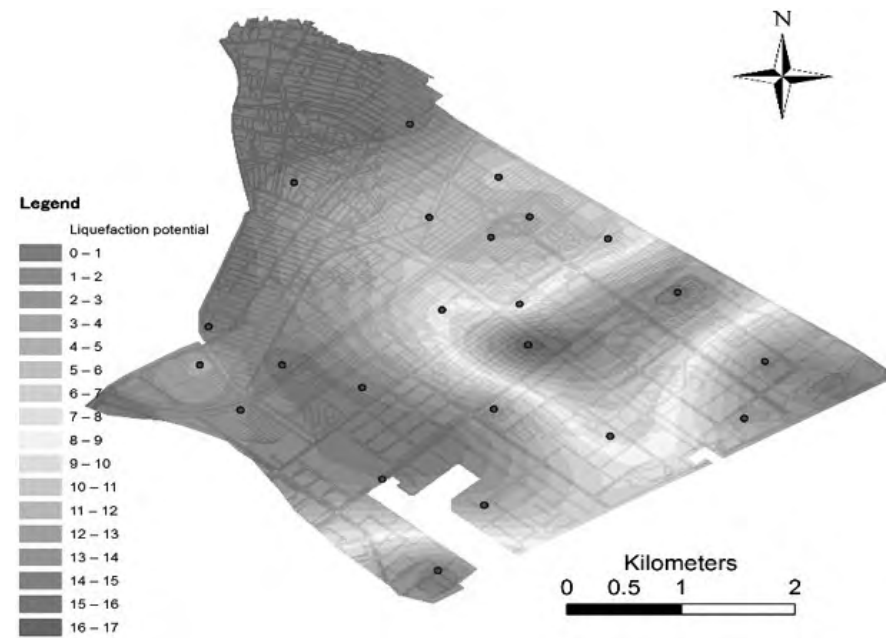

Fig. 3: Liquefaction potential map of the Urayasu area. $r_{d}=1-0.015 \mathrm{z}$

Where, $\mathrm{z}$ is the depth in meters from the ground surface. Similarly, dynamic load or dynamic shear strength ratio during earthquakes is expressed in terms of $\mathrm{R}$ and is calculated based on the relationships from (Japan Road Association 2012).

$R=C_{W} R_{L}$

Where, $\mathrm{Cw}$ is coefficient of earthquake characteristics, and its value is varied with cyclic strength ratio $R L$ as.

$C w=1$ for $(R L \leq 0.1)$

$C w=3.3 R L+0.67$ for $(0.1<R L \leq 0.4)$

$C w=2$ for $(R L>0.4)$

The cyclic strength ratio RL is estimated by

$$
\begin{aligned}
& R_{L}=0.0882 \sqrt{N_{a} / 1.7} \quad \ldots \ldots \ldots \ldots \ldots(5) \text { for } \text { for } N a<14 \\
& R_{L}=0.0882 \sqrt{N_{a} / 1.7}+1.6 * 10^{-6} *\left(N_{a}-14\right)^{4.5} \ldots \ldots .(6) \text { for } N a<14 \\
& N_{a} \text { is corrected } \mathrm{N} \text {-value and estimated as: } N_{a}=N_{1}+\Delta N \ldots .
\end{aligned}
$$

Where $\Delta \mathrm{N}$ is a parameter calculated as a function of fine content. In this paper the percentage of fine content is estimated by using a relationship proposed by (Kamai et.al. 2002)

$$
\begin{aligned}
& \Delta N=0, \text { for }\left(F_{c}<8 \%\right) \\
& \Delta N=20.679 * \log 10(F c)-18 \text { for }(8 \% \leq F c<40 \%) \\
& \Delta N=15.27, \text { for }(F c>40 \%) \\
& N_{1}=170 * N /\left(\sigma_{0}+70\right) \ldots \ldots \ldots . .(8)
\end{aligned}
$$

Where, $\mathrm{N}$ is the number of blows in a Standard Penetration Test (SPT) and $\sigma 0$ ' is the effective stress. The liquefaction potential for each borehole was evaluated by the liquefaction potential index (PL), which is defined as (Iwasaki et al. 1978, 1982):

$$
P_{L}=\int_{0}^{20} F(z) W(z) d z
$$

Where $\mathrm{z}$ is the depth below the ground surface in meters; $W(z)$ is a depth-weighting factor and has a value between 10 and $0.5 \mathrm{z} ; F(z)$ is a function of liquefaction resistance factor; and FL(z) is defined as $F(z)=1-F L(z)$ for $F L(z) \leq 1$ and $F(z)=0$ for $F L(z)>1$. Equation (9) considers only the profile for the top $20 \mathrm{~m}$ and weighs the factor of safety and thickness of potentially liquefiable layers according to the proximity of layers to the ground surface. The liquefaction potential (PL) values calculated from equation (9) ranges from 0 to 100 . The minimum value of 0 is obtained where $F L(z)>1$ over the entire $20 \mathrm{~m}$ depth. The maximum value of 100 is obtained where $F L(z)=0$ over the entire $20 \mathrm{~m}$ depth. In this study, the soil layers above the water table were considered to be non-liquefiable layers. In this study, the peak ground acceleration for the Urayasu area is 173 gal. After calculating the liquefaction potential at each bore hole, the liquefaction potential for the whole area was estimated by interpolating PL values obtained from the 23 boreholes. A kriging method of interpolation was used which considers both the distance and the degree of 
variation among known data points and estimates values in unknown areas (Pokhrel et al. 2010, 2012, 2013).

By using the above explained methodology, the spatial variation of PL for the Urayasu area is prepared as in Fig. 3. Almost all the newly reclaimed area has high liquefaction potential which indicates that the area is very risk for liquefaction for future earthquakes.

\section{Soil subsidence map of Urayasu area}

At the time of 11-March 2011, off the Pacific Coast of Tohoku earthquake the soil liquefaction and soil subsidence severely took place around the Tokyo Bay area, especially in the Urayasu city. Roads, parks, buildings and embankments got subsided. Fig. 4 is a subsidence map of the Urayasu city made after analyzing Digital Surface Model (DSM) data taken before earthquake on 2006 and after the earthquake 2011. This map is used as a spatial distribution of soil subsidence map.

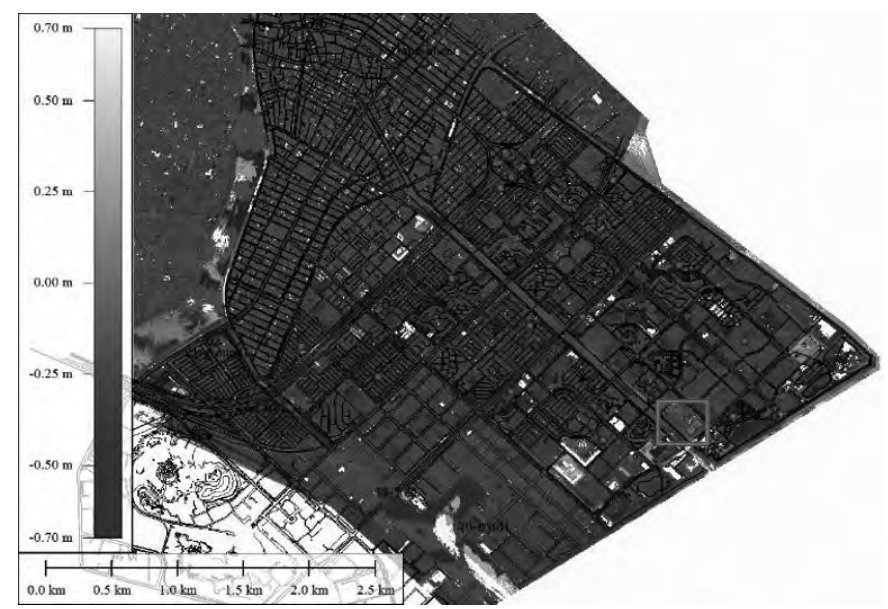

Fig. 4: Soil subsidence map of Urayasu area (Konagai et al. 2013) with observation area red square.

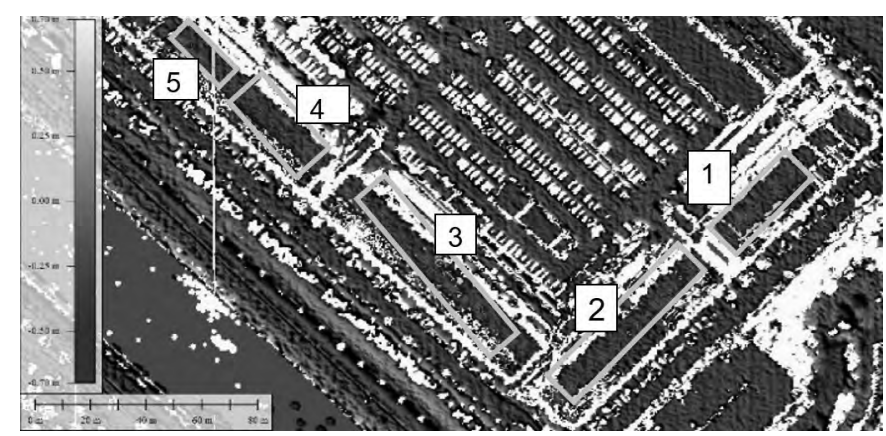

Fig. 5: Five different buildings in the zoomed area.

\section{ANALYSIS AND DISCUSSION}

An attempt was made in this study to measure soil subsidence in the high liquefaction potential area. For this purpose, a small area enclosed in a red square in Fig. 4 was selected for the detail

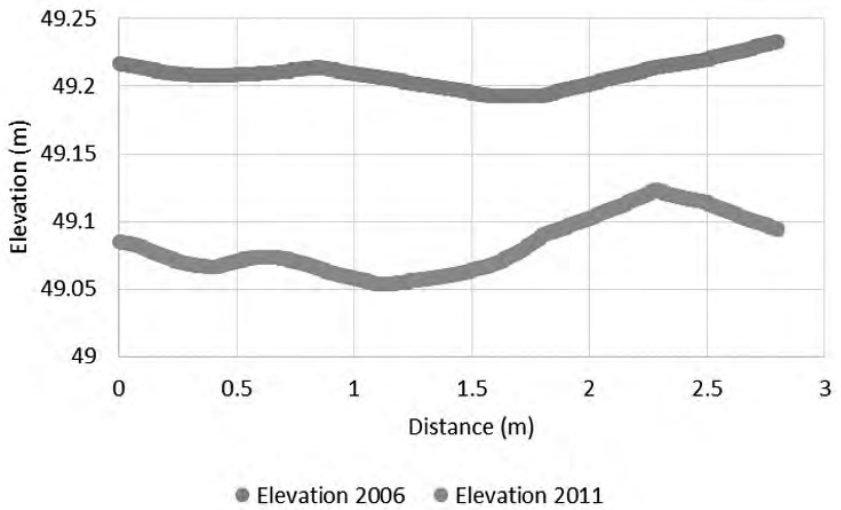

Fig. 6: Elevation in 2006 and 2011 a profile in a small area.

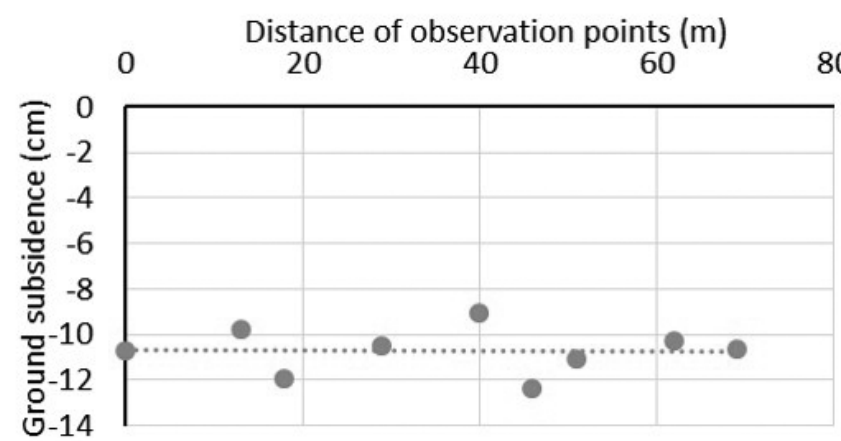

Fig. 7: Trend curve of the average subsidence for one building.

Table 1: Average subsidence measured in the study area.

\begin{tabular}{|l|l|}
\hline Building & Average Subsidence $(\mathrm{cm})$ \\
\hline 1 & -8 \\
\hline 2 & -10.5 \\
\hline 3 & -11 \\
\hline 4 & -6.5 \\
\hline 5 & -11 \\
\hline
\end{tabular}

Table 2: Average subsidence measured outside the building in the study area

\begin{tabular}{|l|l|}
\hline Small area no. & Average Subsidence $(\mathrm{cm})$ \\
\hline 1 & 0.5667 \\
\hline 2 & 6.3097 \\
\hline 3 & 1.3044 \\
\hline 4 & -3.995 \\
\hline 5 & -0.336 \\
\hline 6 & -2.35 \\
\hline 7 & -1.771 \\
\hline
\end{tabular}

study. This area lies within the high liquefaction potential area in the liquefaction potential distribution map (Fig. 3). Fig. 5 is a zoomed map of this square area. As shown in this zoomed area (Fig. 5), there are five different high rise buildings. On the top of each building a small area is taken and a profile is drawn 
as in the fig.6. In this profile the two lines are the elevation curve in 2006 and 2011. The difference between the elevation in 2006 and 2011 is the net subsidence value for the point. In this similar way, we draw many such types of the small area and draw the profile. For each profile the average subsidence value is calculated. The calculated average subsidence value and distance of the points is plotted in the graph (as in Fig. 7) and found the trend curve for the subsidence of the corresponding building. Fig. 7 is an example for the building 2 where the average subsidence of the building is $10.5 \mathrm{~cm}$. Similarly, this process was done for all the buildings. There are different in subsidence value for different buildings. The building 1 has -8 $\mathrm{cm}$ subsidence but building 2 has $-10.5 \mathrm{~cm}$. The building 4 has least subsidence $(-6.5 \mathrm{~cm})$ and building 3 and 5 has maximum $(-11 \mathrm{~cm})$ subsidence. The building number and corresponding subsidence value is presented in the table 1 .

Most of the points in the high liquefaction potential area has higher subsidence value and vice versa. Similar process and analysis is done for the area lying outside of the building. From the outer part (parking lot, open space, and small roads) of the building soil subsidence were found less than the subsidence within the building area Table 2 . Some of the points show positive subsidence i.e upliftment of the ground too.

\section{CONCLUSION}

The off the Pacific Coast of Tohoku Earthquake 11 March 2011 has caused severe soil liquefaction resulting soil subsidence in the newly reclaimed land of Urayasu area. To identify the nature and extent of future liquefaction and soil subsidence within the reclaimed area, the liquefaction potential map was prepared using 23 boreholes within the Urayasu area. This map has shown that the most area of the Urayasu city lies in highly vulnerable for liquefaction. The soil subsidence map of the same area was prepared by analyzing two sets of DSM data. The soil subsidence in the high liquefaction potential area was analyzed with references to high rise buildings and nearby open ground space. The high rise building has significant subsidence value (greater than $10 \mathrm{~cm}$ ). The other area has varied soil subsidence value with liquefaction potential.

\section{ACKNOWLEDGMENTS}

The author is grateful to the Japan Society for the Promotion of Science (JSPS) for the postdoctoral research fellowship to work at the Institute of Industrial Science, the University of Tokyo. Similarly, authors gratitude with Kazuhiro Kajihara, graduate student at Yokahama National University for his help during data collection and analysis.

\section{REFERENCES}

Habibullah, B. M., Pokhrel, R. M., Kuwano, J. and Tachibana, S., 2012, GIS-based Soil liquefaction hazard zonation due to earthquake using geotechnical data. Int. Jour. Geomate, v. 2(1), pp. 154-160.

Iwasaki, T., Tatsuoka, F., Tokida, K. and Yasuda, S., 1978, A practical Method for Assessing Soil Liquefaction Potential Based on Case Studies at Various Sites in Japan, Proc. 2nd International Conference on Microzonation, San Francisco, v. 2, pp. 885896.

Iwasaki, T., Tokida, K., Tatsuoka, F., Watanabe, S., Yasuda, S., and Sato, H., 1982, Microzonation for soil liquefaction potential using simplified methods, Proceedings of 3rd International Earthquake Microzonation Conference, Seattle, pp. 1319-1330.

Japan road association, 2012, Seismic designed specifications for Highway bridge volume V.

Kamei, M., Morimoto, I., Yasuda, S., Shimizu, Y., Koganemaru, K., Ishida, E., 2002, A consideration on grain size of alluvial sands and relationships between fines and liquefaction resistance in Tokyo lowland. Soil and Foundations, v. 42(4), pp. 101-110 (in Japanese).

Konagai, K., kiyota, T., Suyama, S., Asakura, T., Shibuya, K., Eto, C., 2013, Maps of soil subsidence for Tokyo bay shore areas liquefied in the March 11th, 2011 off the Pacific Coast of Tohoku Earthquake. Soil Dynamics and Earthquake Engineering, v. 53, pp. 240-253.

Pokhrel, R.M., Kuwano, J., Tachibana, S., 2010, Liquefaction hazard zonation mapping of the Saitama City, Japan. Jour. Nepal Geol. Soc., v. 40, pp. 69-76.

Pokhrel, R.M., Kuwano, J., Tachibana, S., 2012, Geostatistical analysis for spatial evaluation of liquefaction potential in Saitama City. Lowland Tech. Int., v. 14(1), pp. 45-51.

Pokhrel, R.M., Kuwano, J., Tachibana, S., 2013, A kriging method of interpolation used to map liquefaction potential over alluvial ground. Engineering Geol., v. 152, pp. 26-37.

Urayasu City, 2012, Data compiled by the technical committee on measures against Liquefaction URL http://www.city.urayasu. chiba.jp/menu11324.html (in Japanese).

Yasuda, S., Harada, K., Ishikawa, K, Kanemaru, Y., 2012, Characteristics of liquefaction in Tokyo Bay area by the 2011 Great East Japan Earthquake. Soils and Foundations, v. 52(5), pp. 793-810. 